\title{
Icariin-mediated expression of cardiac genes and modulation of nitric oxide signaling pathway during differentiation of mouse embryonic stem cells into cardiomyocytes in vitro ${ }^{1}$
}

\author{
Dan-yan ZHU, Yi-jia LOU² \\ Department of Pharmacology and Toxicology, College of Pharmaceutical Sciences, Zhejiang University, Hangzhou 310031, China
}

\section{Key words}

embryonic stem cells; cardiomyocytes; icariin; cardiac-specific genes; cAMP; cGMP; nitric oxide

\footnotetext{
${ }^{1}$ Project supported by the National Natural Sciences Foundation of China (№ 30171121), the Key Grant of the Chinese Ministry of Education (No 03088), and the International Joint Key Grant of Zhejiang Province (No 2003C24005).

${ }^{2}$ Correspondence to Prof Yi-jia LOU. Phn/Fax 86-571-8721-7206.

Emailyijialou@zju.edu.cn
}

Received 2005-08-05

Accepted 2005-11-06

doi: $10.1111 / \mathrm{j} .1745-7254.2006 .00275 . \mathrm{x}$

\begin{abstract}
Aim: To investigate effects of icariin on cardiac gene expression and the modulation of nitric oxide (NO) signal transduction during the differentiation of embryonic stem (ES) cells into cardiomyocytes in vitro. Methods: The expression levels of cardiac developmental-dependent genes were measured using reverse transcription-polymerase chain reaction (RT-PCR). The chronotropic responses of cardiomyocytes to $\beta$-adrenoceptor stimulation were determined. The levels of cAMP and cGMP in ES cells were measured using radioimmunoassay. Endogenous NO levels were measured by using the Griess reaction. Aminoguanidine (AG) was used to confirm the influence of icariin on the endogenous NO signal pathway. Results: Icariin significantly elevated mRNA levels of cardiac transcription factors GATA4 and $N k x 2.5$, and cardiac-specific $\alpha-M H C, M L C-2 v$ and $\beta$ $A R$ genes in a concentration- and time-dependent manner $(P<0.05)$. Cardiomyocytes derived from embryoid body (EB) treated with icariin were more sensitive to isoprenaline $(P<0.01)$. Treatment of ES cells with icariin resulted in a continued elevation in the cAMP/cGMP ratio before a shift to the cardiomyocyte phenotype $(P<0.05)$. AG decreased the NO level, and delayed and decreased the incidence of contracting EB to only approximately $35 \%$ on $\mathrm{d} 5+11$, an effect that could be rescued by icariin. When cells were cocultured with icariin and AG, the percentage of beating EB reached a peak level of $73 \%$ on $\mathrm{d} 5+11(P<0.05)$. Conclusion: The inducible effects of icariin were partly related to increase in the expression of cardiac developmental-dependent genes, and elevation of the cAMP/cGMP ratio in ES cells, as well as upregulation of endogenous NO generation during the early stages of cardiac development.
\end{abstract}

\section{Introduction}

Herba Epimedii is an important traditional Chinese herbal medicine that is widely used as a tonic, aphrodisiac, and antirheumatic in China. The content of icariin, its effective ingredient, has been used as a quality control standard. In our previous work, the specific properties of embryonic stem (ES) cells and standard culture methods ${ }^{[1]}$ were used to confirm the inducible effects of icariin and its two metabolites on the differentiation of ES cells into cardiomyocytes in vitro ${ }^{[2]}$. Icariin at a concentration of $1 \times 10^{-7} \mathrm{~mol} / \mathrm{L}$ facilitates the directional differentiation of ES cells into cardiomyocytes. Cardiomyocytes are characterized by the expression of sarcomeric proteins, $\alpha$-actinin and cardiac troponin T. Icariin has been found to have effects on regulation of the cell cycle, induction of apoptosis, as well as modulation of p53 during the early differentiation of ES cells and cardiac development, by using flow cytometry, reverse transcription-polymerase chain reaction (RT-PCR) and Western blot analysis $^{[3]}$. But the other possible mechanisms by which icariin inducibly affects the directional differentiation of ES cells into cardiomyocytes are still not completely understood 
and it is worthwhile to investigate them further.

Cardiac-specific genes, proteins, receptors and signaling molecules are expressed in a developmentally controlled manner during cardiac differentiation of ES cells in vitro, which closely recapitulate the developmental pattern of early cardiogenesis in vivo ${ }^{[4]}$. With a view to detecting the targets of icariin action during the promotion of ES cells to differentiate, the expression of cardiac developmentaldependent genes was measured using RT-PCR, and the chronotropic responses of cardiomyocytes to $\beta$-adrenoceptor stimulation were determined.

The second messengers, cAMP and cGMP, play an important part in regulating cellular proliferation and differentiation. It is crucial that the correct $\mathrm{cAMP} / \mathrm{cGMP}$ ratio is maintained. Moreover, if a compound heightens the cAMP level of cells, it may facilitate differentiation and inhibit proliferation $^{[5,6]}$. Therefore, the levels of cAMP and cGMP in ES cells treated with icariin were measured to clarify the possible actions of icariin on early differentiation events before a shift to the cardiomyocyte phenotype.

$\mathrm{NO}$, a potential differentiation signal molecule, is important for cardiac development. It has been reported that incubation of embryoid body (EB) with nitric oxide synthase (NOS) inhibitors resulted in a pronounced differentiation arrest of cardiomyocytes, whereas this effect could be reversed by coapplication of the NO donor. In the development of cardiogenesis, the classic mode of action of NO is through intracellular signaling cascades via the activation of cGMP ${ }^{[7]}$. When administered orally, icariin can increase the mRNA and protein expression of eNOS and iNOS as a result of regulating the endogenous NO level to enhance erectile function ${ }^{[8]}$. In the present study, we tested the hypothesis that icariin promoted the differentiation of ES cells into cardiomyocytes in part through regulating the endogenous NO signaling pathway. The concentration of endogenous NO in ES cells during differentiation was evaluated by using the Griess reaction. In addition, aminoguanidine (AG), an effective and selective inhibitor of iNOS, was used to explore the influence of icariin on endogenous NO levels in the differentiation of ES cells into cardiomyocytes, and to confirm the targets of icariin action.

\section{Materials and methods}

Cells, drugs, and reagents The permanent ES cell line D3 (ES-D3) was obtained from the American Type Culture Collection (CRL-1934). Icariin was obtained from the Drug Biology Product Examination Bureau, Beijing, China (batch № 0737-200011, purity 99\%); retinoic acid (RA), $\beta$-mercapto- ethanol, aminoguanidine (AG) and monoclonal anti-sarcomeric-actinin were purchased from Sigma (St Louis, MO, USA); Dulbecco's modified Eagle's minimal essential medium (DMEM) was purchased from Gibco Invitrogen Corporation (Grand Island, NY, USA). Fetal calf serum (FCS) and the non-essential amino acids (NEAA) were purchased from Hyclone (Logan, UT, USA). Mitomycin C was purchased from Kyowa Hakko Kogyo (Tokyo, Japan); and recombinant mouse leukemia inhibitory factor (LIF) was purchased from Chemicon International (Temecula, CA, USA). The fluorescein isothiocyanate (FITC)-conjugated $\mathrm{F}(\mathrm{ab})_{2}$ fragment of affinity-purified goat anti-mouse IgG was obtained from Rockland (Gilbertsville, PA, USA). The reagents for the RTPCR were purchased from the Shanghai Sangon Biological Engineering Technological and Service Company (Shanghai, China). ${ }^{125}$ I-cAMP and ${ }^{125}$ I-cGMP were obtained from the Shanghai University of Traditional Chinese Medicine.

ES cell culture and icariin/aminoguanidine treatment ES-D3 cells were cultured in an undifferentiated state on primary cultures of mouse embryonic fibroblasts (MEF) cells in DMEM, supplemented with $10 \% \mathrm{FCS}, 0.1 \mathrm{mmol} / \mathrm{L} \beta$ mercaptoethanol, NEAA and $1 \times 10^{6} \mathrm{U} / \mathrm{L}$ LIF. Cultures of differentiating ES cells were established by the formation of EB in hanging drop cultures ${ }^{[2,9,10]}$ with differentiation medium. On d 5, EBs were plated separately onto gelatin-coated 24well culture plates, and at that time, icariin was added to the medium at concentrations of $1 \times 10^{-7}, 1 \times 10^{-8}$, or $1 \times 10^{-9} \mathrm{~mol} / \mathrm{L}$, on the basis of preliminary test results. EBs treated with $1 \times 10^{-8} \mathrm{~mol} / \mathrm{L}$ RA or with $0.1 \%$ dimethyl sulfoxide $\left(\mathrm{Me}_{2} \mathrm{SO}\right)$ solvent were used as positive or negative controls, respectively. To explore whether icariin promoted the differentiation of ES cells into cardiomyocytes in part through regulating the endogenous $\mathrm{NO}$ signaling pathway, $\mathrm{AG}$ at a concentration of $1 \times 10^{-3} \mathrm{~mol} / \mathrm{L}$ was added to differentiation medium together with icariin on $\mathrm{d} 5$ and maintained until $\mathrm{d}$ 5+11 (ie, $11 \mathrm{~d}$ after EB was plated onto gelatin-coated culture plates on d 5). EB was observed with a light microscope every day to record the number of spontaneously beating EB.

In the experiment, $\mathrm{d} 1$ corresponds to the day of dissociation of ES cells from MEF cells, and the initiation of differentiation by the formation of EB. To identify whether the observed cell types derived from ES-D3 cells were cardiomyocytes, indirect immunofluorescence for cardiac-specific protein was carried out according to a method published elsewhere $^{[2,3]}$.

Detection of cardiac-specific transcripts by semi-quantitative RT-PCR analysis Total RNA was isolated from EBs $(n=20)$ induced by $1 \times 10^{-7}, 1 \times 10^{-8}$ or $1 \times 10^{-9} \mathrm{~mol} / \mathrm{L}$ icariin, 
$1 \times 10^{-8} \mathrm{~mol} / \mathrm{L}$ RA or solvent at different time points by using Trizol reagent. After extraction, mRNA was precipitated and dissolved in a $0.1 \%$ diethylpyrocarbonate solution. To synthesize first strand cDNA, $7 \mu \mathrm{L}$ total RNA was incubated in $0.5 \mu \mathrm{g}$ of oligo $(\mathrm{dT})_{6}$ primer and $5 \mu \mathrm{L}$ deionized water at $65^{\circ} \mathrm{C}$ for $15 \mathrm{~min}$. Reverse transcription reactions were performed with $200 \mathrm{U}$ M-MuLV reverse transcriptase in $5 \times$ reaction buffer and $1 \mathrm{mmol} / \mathrm{L} \mathrm{dNTP}$ mixture for $1 \mathrm{~h}$ at $42^{\circ} \mathrm{C}$. Multiplex polymerase chain reaction mixtures of $50 \mu \mathrm{L}$ contained $1 \mu \mathrm{L}$ of the RT reaction product, $10 \times \mathrm{PCR}$ buffer, $25 \mathrm{U}$ Taq polymerase, $1 \mu \mathrm{L}$ of $10 \mathrm{mmol} / \mathrm{L} \mathrm{dNTP} \mathrm{mixture,} \mathrm{and} 30 \mathrm{pmol}$ of each primer. The specific primer pairs designed by using Primer 3.0 software and published sequences were as follows (Table 1):

For the semi-quantitative determination of $N k x 2.5$, $G A T A 4, \alpha-M H C, M L C-2 v$ and $\beta$-AR mRNA levels, the products of the reverse transcription reactions were denatured for $3 \mathrm{~min}$ at $94{ }^{\circ} \mathrm{C}$, followed by 35 cycles ( $\left.N k \times 2.5\right), 35$ cycles (GATA4), 40 cycles $(\alpha-M H C), 45$ cycles $(M L C-2 v), 40$ cycles $(\beta-A R)$ or 30 cycles $(\beta$-actin) of amplification with Ampli Taq DNA polymerase as follows: $45 \mathrm{~s}$ denaturation at $94{ }^{\circ} \mathrm{C}, 40 \mathrm{~s}$ annealing at $54.0^{\circ} \mathrm{C}(N k x 2.5$ and $G A T A 4), 66.4{ }^{\circ} \mathrm{C}(a-M H C)$, $61.1^{\circ} \mathrm{C}(M L C-2 v), 54.0^{\circ} \mathrm{C}(\beta-A R)$ or $55.0^{\circ} \mathrm{C}(\beta$-actin $)$, then 45 s elongation at $72{ }^{\circ} \mathrm{C}$. The PCR products were separated by $1.5 \%$ agarose gel electrophoresis, visualized with ethidium bromide staining, and quantified using a Bio-imaging Analyzer (Bio-Rad,CA,USA), and the density of the products were quantitated using Quantity One (version 4.2.2) software (Bio-Rad).

Measurement of contraction of cardiomyocytes derived from ES-D3 cells The in vitro function of ES-D3 cell-derived cardiomyocytes was examined by evaluating the chronotropic effects of cardio-active drugs ${ }^{[12]}$. Isoprenaline (a $\beta$ AR agonist) was cumulatively added to the pulsating clus- ters of EB induced by $1 \times 10^{-7} \mathrm{~mol} / \mathrm{L}$ icariin, $1 \times 10^{-8} \mathrm{~mol} / \mathrm{L}$ RA or solvent on $\mathrm{d} 5+5$, d 5+9, and $\mathrm{d} 5+13$, respectively. Then the frequencies were measured in control (ie, the basal level of beating frequency, before agonist treatment) and agonisttreated variants to create dose-response curves. Measurements were also carried out in the presence of the antagonist propranolol. Images of the beating cardiomyocytes were monitored with a charge coupled device (CCD) video camera attached to the microscope observation port, and also displayed on a computer screen. The frequency of contraction was detected by using a photoelectricity transformation system, which transformed photic signals into electrical signals $^{[13]}$.

cAMP and cGMP determination assay To clarify the mechanism by which icariin affects the early differentiation of ES cells before a shift to the cardiomyocyte phenotype, cAMP and cGMP levels in ES cells were measured by using $a^{125}$ I-cAMP and ${ }^{125}$ I-cGMP double antibody radioimmunoassay method ${ }^{[14]}$. ES-D3 cells were cultivated without MEF feeders and LIF, and treated with $1 \times 10^{-7} \mathrm{~mol} / \mathrm{L}$ icariin or $1 \times 10^{-8}$ mol/L RA. After 24-48 h, the cells were harvested, placed into a polypropylene tube and centrifuged. The supernatant was removed and $1 \mathrm{~mL}$ acetic acid buffer $(\mathrm{pH} 4.5)$ at $4{ }^{\circ} \mathrm{C}$ was added to the cell pellet. Then samples were repeatedly frozen in liquid nitrogen and quickly melted in warm water (5 times). Protein was removed by centrifugation at $5000 \times g$ for $30 \mathrm{~min}$.

Measurement of supernatant NO production Supernatant NO concentration was measured by using the Griess reaction ${ }^{[14]}$. The nitrite concentration was determined by using a curve calibrated with a sodium nitrite standard.

Statistical analysis Data were expressed as Mean \pm SD. At least 3 independent experiments were carried out to cal-

Table 1. Primer sequences for RT-PCR.

\begin{tabular}{|c|c|c|}
\hline Genes & Forward (F) and Reverse (R) primer sequences & Product size $(b p)$ \\
\hline \multirow[t]{2}{*}{$N k \times 2.5$} & F CAAGTGCTCTCCTGCTTTCC & 136 \\
\hline & R GGCTTTGTCCAGCTCCACT & \\
\hline \multirow[t]{2}{*}{ GATA4 } & F TCTCACTATGGGCACAGCAG & 135 \\
\hline & R GCGATGTCTGAGTGACAGGA & \\
\hline \multirow[t]{2}{*}{$\alpha-M H C^{[11]}$} & F CTGCTGGAGAGGTTATTCCTCG & 301 \\
\hline & R GGAAGAGTGAGCGGCGCATCAAGG & \\
\hline \multirow[t]{2}{*}{$M L C-2 v^{[11]}$} & F TGTGGGTCACCTGAGGCTGTGGTTCAG & 189 \\
\hline & R GAAGGCTGACTATGTCCGGGAGATGC & \\
\hline \multirow[t]{2}{*}{$\beta-A R$} & F GTAACGTGCTGGTGATCGTG & 183 \\
\hline & R AAGTCCAGAGCTCGCAGAAG & \\
\hline \multirow[t]{2}{*}{$\beta$-actin } & F TGACGGGGTCACCCACACTGTGCCCATCTA & 660 \\
\hline & R CTAGAAGCATTTGCGGTGGACGATGGAGGG & \\
\hline
\end{tabular}


culate mean. Statistical significance was evaluated with oneway ANOVA by using SPSS 10.0 for Windows. $P<0.05$ was considered statistically significant.

\section{Results}

Identification of cardiomyocytes derived fromES-D3 cells Apparent cell morphological changes during the course of differentiation were shown in Figure 1. The differentiated beating cardiac cells stained positively with anti- $\alpha$-actinin $\mathrm{mAb}$. These results accorded with those of our previous studies $^{[2,3]}$.

Expression of cardiac-specific genes during the early cardiac developmental stage Cardiomyocytes from EB expressed the cardiac transcription factors GATA4 and $N k \times 2.5$, as well as the cardiac-specific genes $\alpha-M H C, M L C$ $2 v$ and $\beta-A R$. Icariin significantly upregulated the mRNA levels of transcription factors GATA4 and $N k \times 2.5$ from the onset of cardiac differentiation $(P<0.01)$. The mRNA levels of $\alpha-M H C, M L C-2 v$ and $\beta-A R$ of cells in the presence of icariin increased during the early cardiac developmental stage in a concentration- and time-dependent manner $(P<0.05)$. In particular, $1 \times 10^{-7} \mathrm{~mol} / \mathrm{L}$ icariin-induced $M L C$ - $2 v$ expression was detected as early as d 5+2, whereas increased expression in control cells was not observed until d 5+7 (Figure 2).

Chronotropic responses of ES-D3 cell-derived cardiomyocytes The spontaneously beating capacity of ES cellderived cardiomyocytes enables the investigation of the chronotropic effect of cardioactive substances by measuring the beating frequency of cardiac cells ${ }^{[12]}$. A positive chronotropic response was observed after administration of the $\beta$-agonist isoprenaline. Furthermore, the effect of isoprenaline on ES-D3 cell derived cardiomyocytes was different in the early and late developmental stages. The beating EBs early on $\mathrm{d} 5+5$ were insensitive to isoprenaline (Figure $3 \mathrm{~A})$. In an intermediate phase ( $\mathrm{d} 5+9)$, the beating frequency was significantly increased in the presence of isoprenaline in a concentration-dependent manner $(P<0.01)$. The frequency of beating EB treated with $1 \times 10^{-7} \mathrm{~mol} / \mathrm{L}$ icariin was increased by $20 \%$ when $1 \times 10^{-11} \mathrm{~mol} / \mathrm{L}$ isoprenaline was added. As the concentration of isoprenaline increased gradually to $1 \times 10^{-6} \mathrm{~mol} / \mathrm{L}$, the frequency was increased by approximately $80 \%$, whereas the corresponding increase was only $50 \%$ for controls (Figure $3 \mathrm{~B}$ ). At the terminal differentiation stage $(\mathrm{d} 5+13)$, the cardiomyocytes were highly sensitive to isoprenaline $(P<0.01)$. In the presence of isoprenaline at concentrations ranging from $1 \times 10^{-11}$ to $1 \times 10^{-6} \mathrm{~mol} / \mathrm{L}$, the contraction rate of cardiomyocytes induced by $1 \times 10^{-7} \mathrm{~mol} / \mathrm{L}$ icariin increased from approximately $30 \%$ to $130 \%$ (Figure $3 \mathrm{C}$ ). Propranolol (a $\beta$-adrenoceptor antagonist) at a concen-
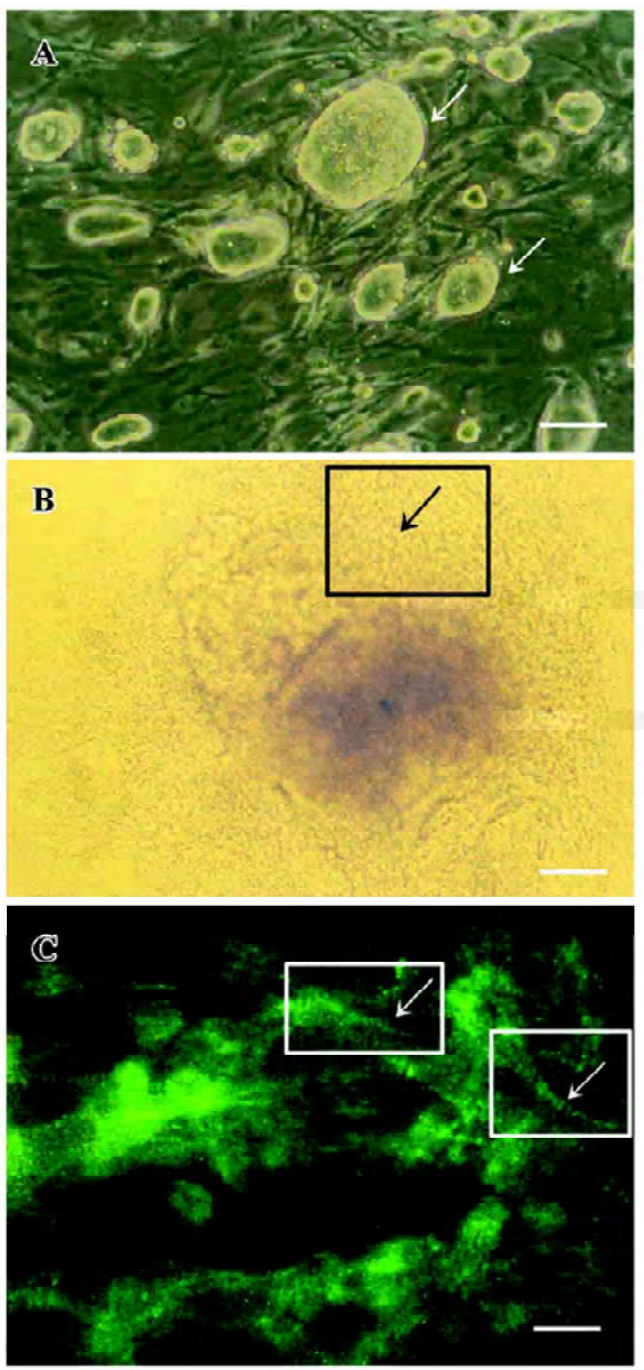

Figure 1. (A) Colonies of ES-D3 cells on a feeder layer of murine embryonic fibroblasts (arrows refer to colonies of ES-D3 cells). (B) Synchronously contracting, functional syncytium of cardiac clusters derived from EB treated with $1 \times 10^{-7} \mathrm{~mol} / \mathrm{L}$ icariin on $\mathrm{d} 5+5$ (arrows point to contraction foci). (C) Positive immunostaining with antisarcomeric $\alpha$-actinin $\mathrm{mAb}$ of dispersed cardiomyocytes from beating EB treated with $1 \times 10^{-7} \mathrm{~mol} / \mathrm{L}$ icariin on $\mathrm{d} 5+13$. The identity of the cardiomyocytes was verified by measuring the expression of cardiacspecific sarcomeres. The arrows indicate the sarcomere for $\alpha$-actinin. $\operatorname{Bar}=100 \mu \mathrm{m}(\mathrm{A}, \mathrm{B}), 25 \mu \mathrm{m}(\mathrm{C})$.

tration of $1 \times 10^{-6} \mathrm{~mol} / \mathrm{L}$ caused a reduction in the frequency increase. A representative trace showing the effect of isoprenaline and propranolol on the beat frequency of the cardiomyocytes is shown in Figure 4.

Levels of cAMP and cGMP in ES cells The concentrations of cAMP and cGMP in ES cells were $0.233 \mathrm{nmol} / \mathrm{L}$ and $0.060 \mathrm{nmol} / \mathrm{L}$, respectively, and the cAMP/cGMP ratio was 3.875. When ES cells were treated with icariin at a concentra- 

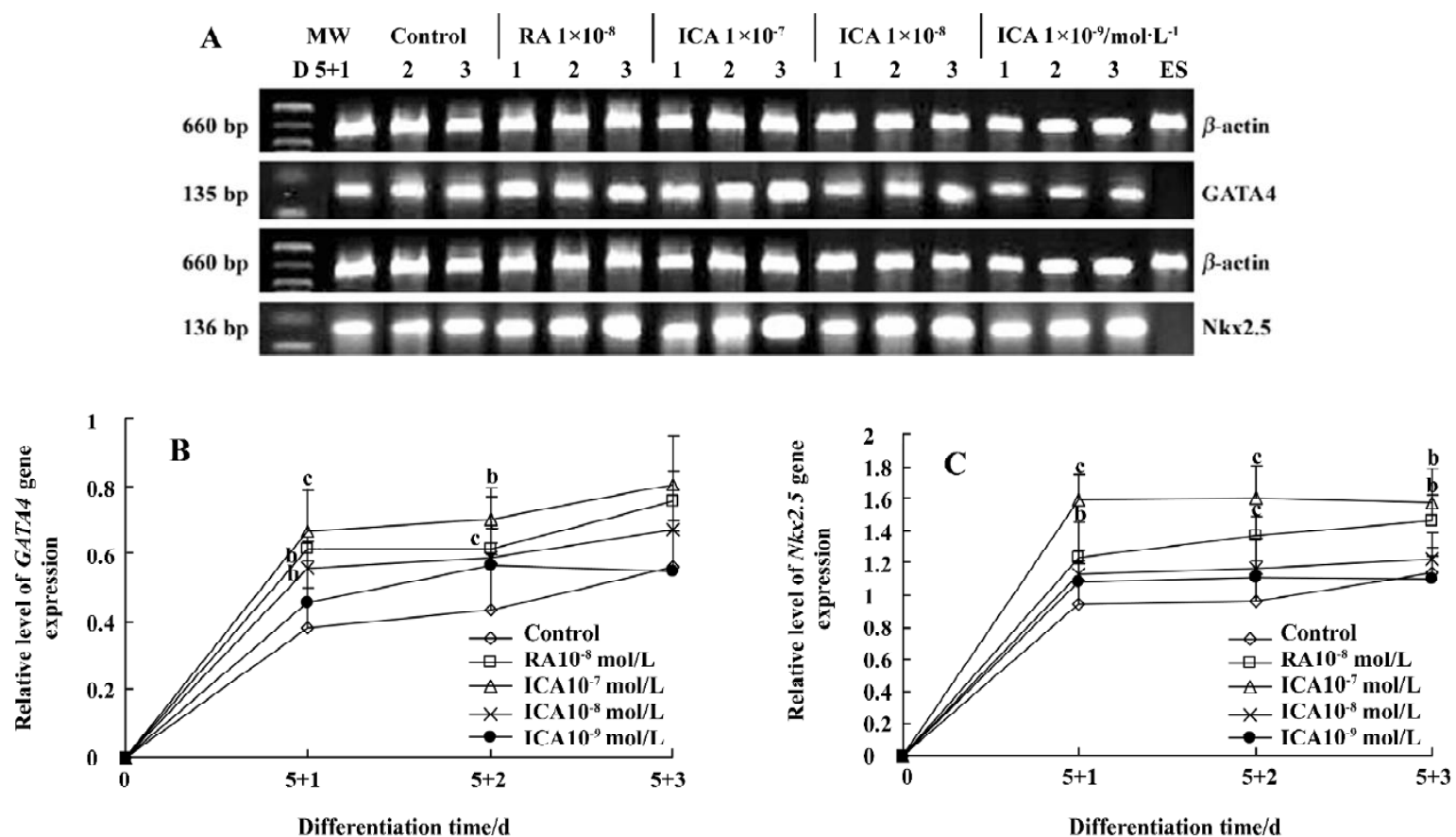

D

\begin{tabular}{l|l|l|l|l} 
MW Control & RA $1 \times 10^{-8}$ & ICA $1 \times 10^{-7}$ & ICA $1 \times 10^{-8}$ & ICA $1 \times 10^{-9} / \mathrm{mol}^{-\mathbf{L}^{-1}}$
\end{tabular}

$\begin{array}{llllllllllllllllll}\text { D 5+2 } & 7 & 11 & 2 & 7 & 11 & 2 & 7 & 11 & 2 & 7 & 11 & 2 & 7 & 11 & \text { H } & \text { ES }\end{array}$

301 bp
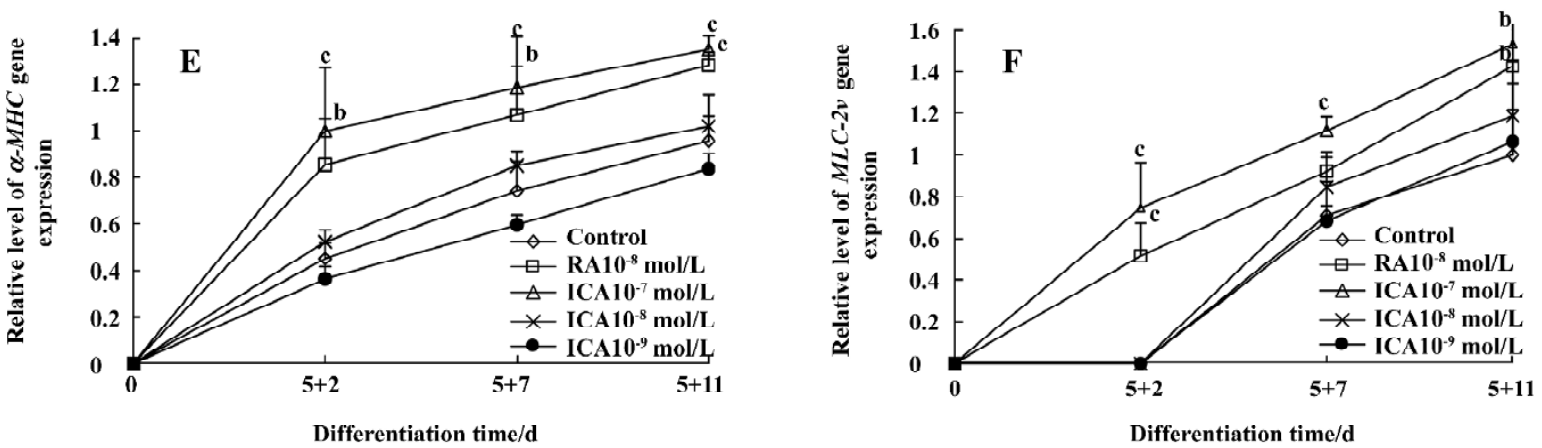

G

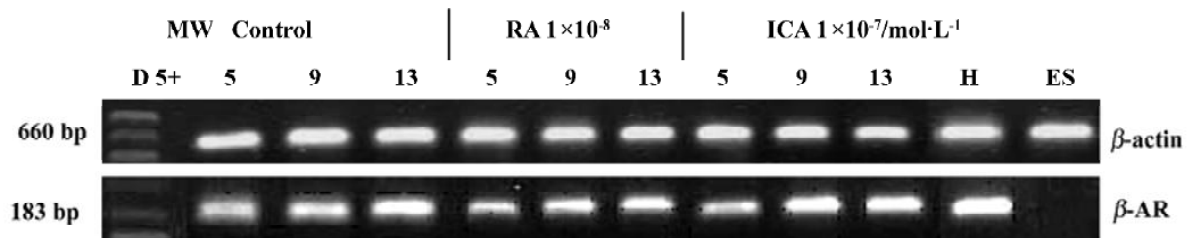




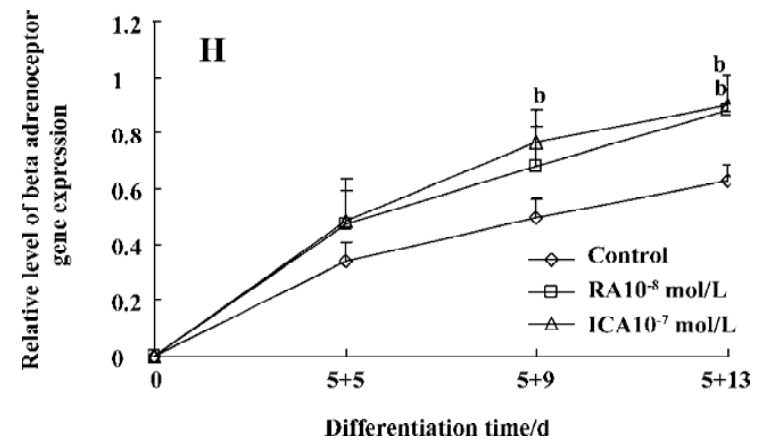

Figure 2. mRNA levels of cardiac genes of icariin (ICA)-treated EB compared with control (untreated) cells analyzed by semi-quantitative RT-PCR. Ethidium bromide-stained gels of PCR products were analyzed by computer-assisted densitometry and the data were plotted for marker genes in relation to $\beta$-actin gene expression. GATA4 and $N k x 2.5(\mathrm{~A}-\mathrm{C}) ; \alpha-M H C$ and $M L C-2 v(\mathrm{D}-\mathrm{F}) ; \beta-A R(\mathrm{G}, \mathrm{H})$. $n=3$ independent RT-PCR experiments. ${ }^{\mathrm{b}} P<0.05,{ }^{\mathrm{c}} P<0.01$ vs control. MW, molecular weight; ES, embryonic stem cells; H, 16 d-old mouse embryonic heart.

tion of $1 \times 10^{-7} \mathrm{~mol} / \mathrm{L}$ for $24 \mathrm{~h}$, the levels of cAMP and cGMP significantly increased to $0.660 \mathrm{nmol} / \mathrm{L}$ and $0.083 \mathrm{nmol} / \mathrm{L}$, respectively $(P<0.05)$. The $\mathrm{cAMP} / \mathrm{cGMP}$ ratio also increased to 7.870 . Treatment of ES cells with icariin for $48 \mathrm{~h}$ caused elevation of the concentration of cAMP and the ratio of cAMP/cGMP $(P<0.01)$, but the concentration of cGMP was barely increased (Table 2).

Production of supernatant NO In the control, supernatant NO production was low. When ES cells were treated with icariin at a concentration of $1 \times 10^{-7} \mathrm{~mol} / \mathrm{L}$ for $24 \mathrm{~h}$ or $48 \mathrm{~h}$, supernatant NO production was markedly elevated $(P<0.05)$. In particular, the NO-cGMP pathway was involved in the early differentiation of ES cells treated with icariin for $24 \mathrm{~h}$. During the course of differentiation (from d 5+2 to d 5+11), icariin facilitated the directional differentiation of ES cells into cardiomyocytes, and supernatant NO generation increased $(P<0.05)$. In the presence of $A G$, an effective and selective inhibitor of iNOS, NO generation during differentiation decreased significantly, but was rescued by icariin $(P<0.05$; Figures 5 and 6).

Inducible effect of icariin together with AG on the directional differentiation of ES-D3 cells into cardiomyocytes To further determine the effects of icariin on modulation of the endogenous NO signaling pathway during the differentiation of ES cells into cardiomyocytes, cultures were supplemented with AG to partially block NO production. Under these conditions, whether the percentage cardiac differentiation was influenced, and the number of spontaneously beating EB were recorded. ES cells were induced into rhyth-
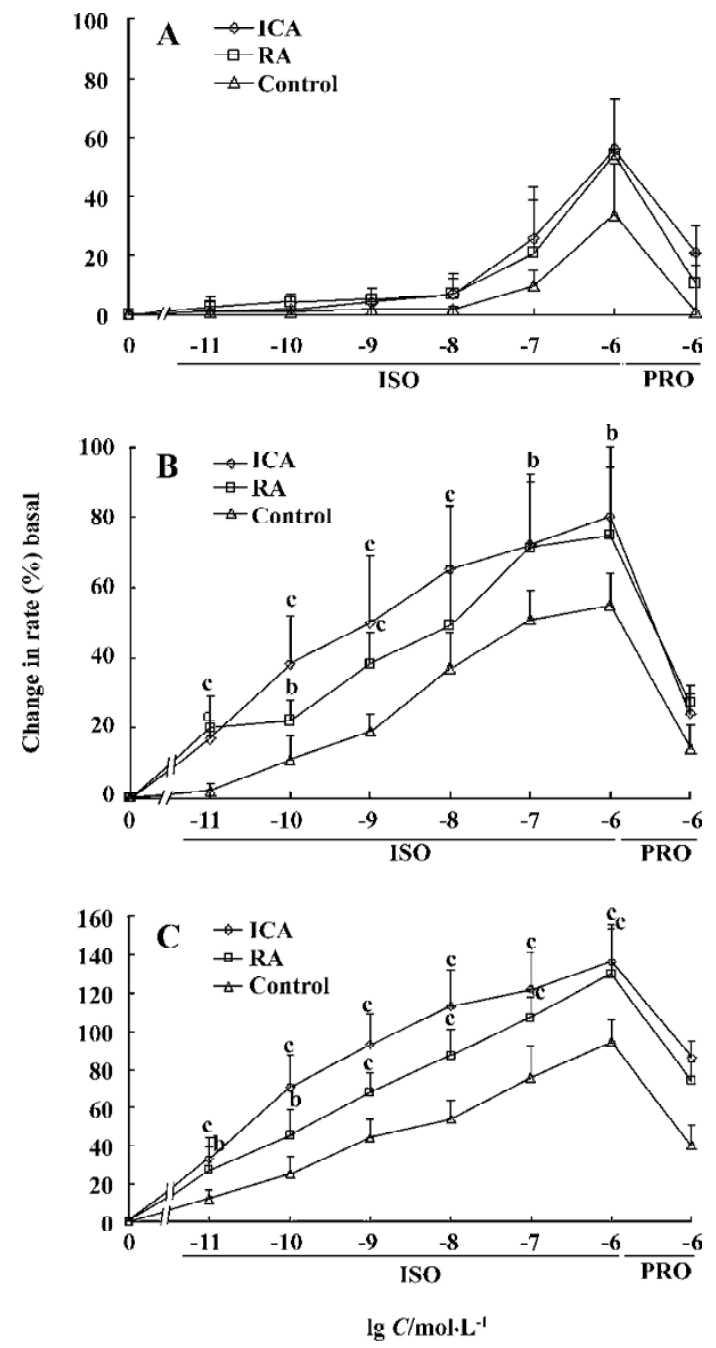

Figure 3. Study of the ES-D3 cell-derived cardiomyocytes for pharmacological responses after treatment with isoprenaline (ISO) and propranolol (PRO) on d 5+5 (A), d 5+9 (B), and d 5+13 (C). EB treated with $1 \times 10^{-7} \mathrm{~mol} / \mathrm{L}$ icariin (ICA). Mean $\pm \mathrm{SD} . n=6$ independent experiments. ${ }^{\mathrm{b}} P<0.05,{ }^{\mathrm{c}} P<0.01$ vs control.

mically beating EB by icariin in a concentration- and timedependent manner ${ }^{[3]}$. The percentage differentiation in cultures containing contracting EB with $1 \times 10^{-7} \mathrm{~mol} / \mathrm{L}$ icariin was approximately $7 \%$ on $\mathrm{d} 5+3$, and reached a peak level of $86 \%$ on $\mathrm{d} 5+11(P<0.05)$. In the control, only approximately $55 \%$ beating EBs were found on $\mathrm{d} 5+11$. AG significantly delayed and decreased the incidence of contracting EB compared with control cells: beating EB was not observed until d 5+4 and the percentage was only approximately $35 \%$ on $\mathrm{d} 5+11$. When icariin-treated cells were co-cultured with AG, AG produced a decrease in the percentage of beating EB to $73 \%$ on d 5+11 compared with cells treated with icariin alone. The potential of EB to undergo cardiac differentiation was 


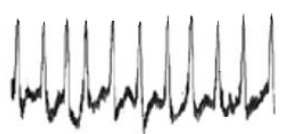

A-1

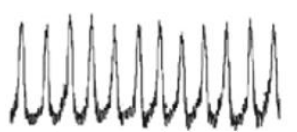

B-1

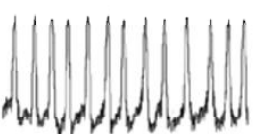

A-2

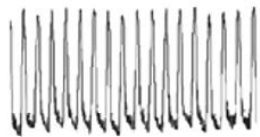

B-2

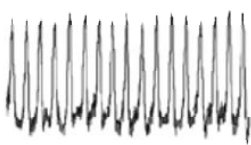

A-3

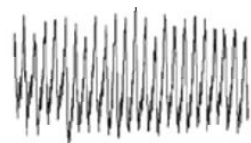

B-3

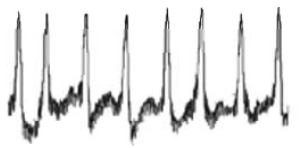

A-4

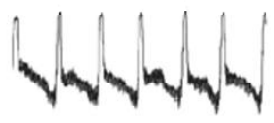

B-4

Figure 4. Example traces showing the beat frequency over $10 \mathrm{~s}$ of the beating cardiomyocytes derived from EB. (A-1-4) EB treated with $0.1 \%$ dimethylsulfoxide on $\mathrm{d} 5+13$ before and during isoprenaline or propranolol exposure. (B-1-4) EB treated with $1 \times 10^{-7}$ mol/L icariin on d 5+13 before and during isoprenaline or propranolol exposure. (A-1) (B-1) Controls (before isoprenaline exposure); (A-2) (B-2) $1 \times 10^{-10}$ mol/L isoprenaline exposure; (A-3) (B-3) $1 \times 10^{-7} \mathrm{~mol} / \mathrm{L}$ isoprenaline exposure; (A-4) (B-4) $1 \times 10^{-6}$ mol/L propranolol exposure.

Table 2. Concentration of cAMP and cGMP in ES cells treated with icariin (ICA) for 24 or 48 h. $n=3$ independent experiments. Mean \pm SD. ${ }^{\mathrm{b}} P<0.05,{ }^{\mathrm{c}} P<0.01$ vs control.

\begin{tabular}{|c|c|c|c|}
\hline Group & $\mathrm{cAMP} / \mathrm{nmol} \cdot \mathrm{L}^{-1}$ & $\mathrm{cGMP} / \mathrm{nmol} \cdot \mathrm{L}^{-1}$ & cAMP/cGMP \\
\hline ES & $0.233 \pm 0.047$ & $0.060 \pm 0.010$ & $3.875 \pm 0.284$ \\
\hline Control & $0.373 \pm 0.100$ & $0.063 \pm 0.006$ & $6.016 \pm 2.021$ \\
\hline $\mathrm{RA} 10^{-8} \mathrm{~mol} / \mathrm{L}$ & $0.863 \pm 0.021^{\mathrm{c}}$ & $0.083 \pm 0.006^{\mathrm{c}}$ & $10.389 \pm 0.674^{\mathrm{b}}$ \\
\hline $24 \mathrm{~h} \mathrm{ICA} 10^{-9} \mathrm{~mol} / \mathrm{L}$ & $0.506 \pm 0.178$ & $0.073 \pm 0.012$ & $6.931 \pm 2.073$ \\
\hline $24 \mathrm{~h} \mathrm{ICA} 10^{-8} \mathrm{~mol} / \mathrm{L}$ & $0.580 \pm 0.151$ & $0.073 \pm 0.012$ & $7.861 \pm 1.214$ \\
\hline $24 \mathrm{~h} \mathrm{ICA} 10^{-7} \mathrm{~mol} / \mathrm{L}$ & $0.660 \pm 0.165^{b}$ & $0.083 \pm 0.006^{\mathrm{c}}$ & $7.870 \pm 1.556$ \\
\hline Control & $0.503 \pm 0.175$ & $0.073 \pm 0.012$ & $6.986 \pm 2.479$ \\
\hline RA $10^{-8} \mathrm{~mol} / \mathrm{L}$ & $1.226 \pm 0.405^{\mathrm{b}}$ & $0.077 \pm 0.021$ & $15.856 \pm 0.964^{\mathrm{c}}$ \\
\hline $48 \mathrm{~h} \mathrm{ICA} 10^{-9} \mathrm{~mol} / \mathrm{L}$ & $1.040 \pm 0.181$ & $0.080 \pm 0.000$ & $11.917 \pm 3.942$ \\
\hline $48 \mathrm{~h} \mathrm{ICA} 10^{-8} \mathrm{~mol} / \mathrm{L}$ & $1.183 \pm 0.432$ & $0.086 \pm 0.012$ & $13.975 \pm 6.119$ \\
\hline $48 \mathrm{~h} \mathrm{ICA} 10^{-7} \mathrm{~mol} / \mathrm{L}$ & $1.554 \pm 0.506^{\mathrm{c}}$ & $0.090 \pm 0.008$ & $18.684 \pm 5.645^{\mathrm{c}}$ \\
\hline
\end{tabular}

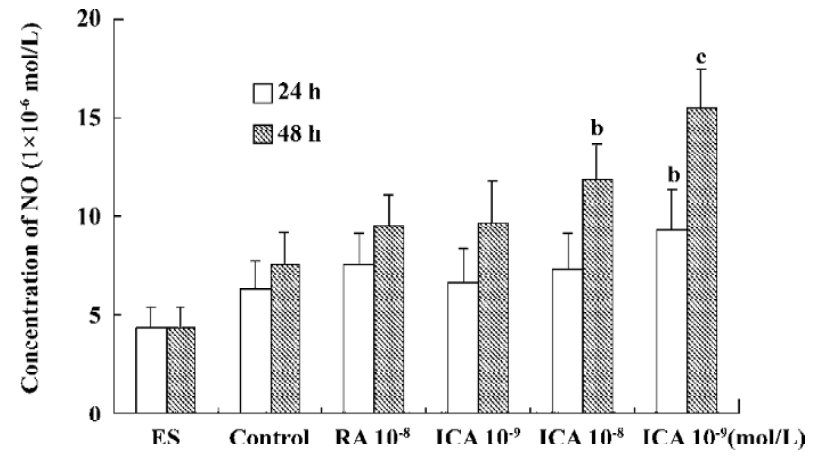

Figure 5. Effects of icariin (ICA) on supernatant NO production in ES cells during early differentiation events before a shift to the cardiomyocyte phenotype. $n=5$ independent experiments. Mean \pm SD. ${ }^{\mathrm{b}} P<0.05,{ }^{\mathrm{c}} P<0.01$ vs control.

significantly enhanced in comparison with that in solvent together with AG treatment starting from d 5+3 $(P<0.05$; Figure 7).

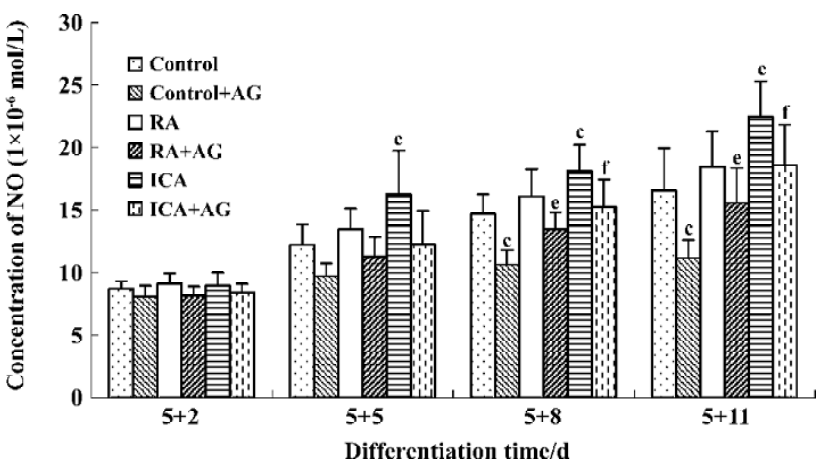

Figure 6. Supernatant NO production during cardiac differentiation from EB. EB was treated with $1 \times 10^{-7} \mathrm{~mol} / \mathrm{L}$ icariin (ICA), $1 \times 10^{-7}$ $\mathrm{mol} / \mathrm{L} \mathrm{ICA}+1 \times 10^{-3} \mathrm{~mol} / \mathrm{L} \mathrm{AG}, 1 \times 10^{-8} \mathrm{~mol} / \mathrm{L} \mathrm{RA}$ (positive control), $1 \times 10^{-8} \mathrm{~mol} / \mathrm{L} \mathrm{RA}+1 \times 10^{-3} \mathrm{~mol} / \mathrm{L} \mathrm{AG}, 0.1 \%$ dimethylsulfoxide (control) or $0.1 \%$ dimethylsulfoxide $+1 \times 10^{-3} \mathrm{~mol} / \mathrm{L} \mathrm{AG.} n=5$ independent experiments. Mean \pm SD. ${ }^{\mathrm{c}} P<0.01$ vs control; ${ }^{\mathrm{e}} P<0.05,{ }^{\mathrm{f}} P<0.01$ vs control+AG. 


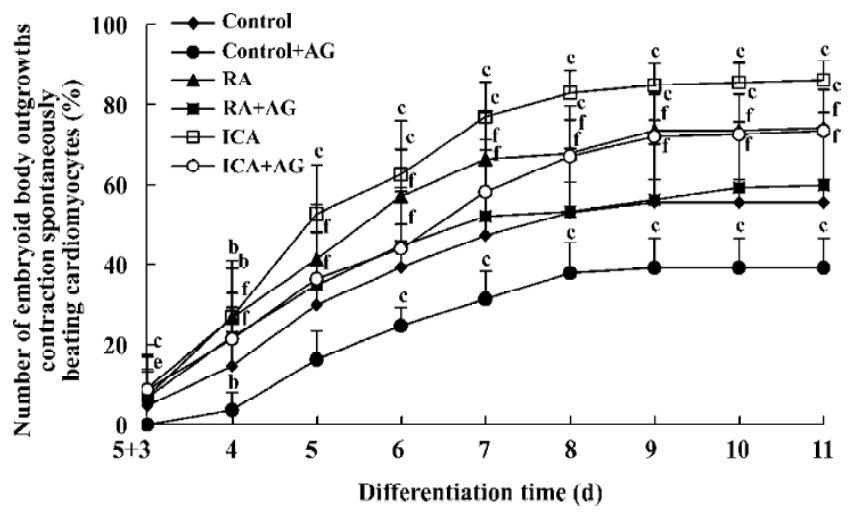

Figure 7. Percentage of beating EB. EB was treated with $1 \times 10^{-7} \mathrm{~mol} / \mathrm{L}$ icariin (ICA) $(n=221 \mathrm{EBs}), 1 \times 10^{-7} \mathrm{~mol} / \mathrm{L} \mathrm{ICA}+1 \times 10^{-3} \mathrm{~mol} / \mathrm{L} \mathrm{AG}(n=219$ EBs), $1 \times 10^{-8} \mathrm{~mol} / \mathrm{L} \mathrm{RA}\left(n=223 \mathrm{EBs}\right.$; positive control), $1 \times 10^{-8} \mathrm{~mol} / \mathrm{L}$ $\mathrm{RA}+1 \times 10^{-3} \mathrm{~mol} / \mathrm{L} \mathrm{AG}(n=216 \mathrm{EBs}), 0.1 \%$ dimethylsulfoxide (control) ( $n=207 \mathrm{EBs}$ ), $0.1 \%$ dimethylsulfoxide $+1 \times 10^{-3} \mathrm{~mol} / \mathrm{L} \mathrm{AG}(n=229 \mathrm{EBs})$. EB was plated at $\mathrm{d} 5$ and the number of beating EB was evaluated during culture from $\mathrm{d} 5+3$ to $\mathrm{d} 5+11 . n=7$ independent experiments. Mean \pm SD. ${ }^{\mathrm{b}} P<0.05,{ }^{\mathrm{c}} P<0.01$ vs control. ${ }^{\mathrm{e}} P<0.05,{ }^{\mathrm{f}} P<0.01$ vs control+AG.

\section{Discussion}

Our experiments demonstrated that icariin markedly enhanced the mRNA levels of GATA4, Nkx2.5, $\alpha-M H C, M L C$ $2 v$ and $\beta$ - $A R$ at the early stage of differentiation. It has been reported that the GATA4 and $N k x 2.5$ transcription factors appear before other cardiac genes are expressed ${ }^{[15]}$. Myocardial genes such as $\alpha-M H C$ are expressed relatively early during the course of cardiogenesis ${ }^{[16]}$; however, $M L C-2 v$ mRNA is expressed at high levels relatively late, and is spatially restricted to the ventricular area ${ }^{[17]}$. In the present study RT-PCR analysis revealed that cardiac differentiation of ES cells induced by icariin recapitulated this developmental pattern, as GATA4 and $N k x 2.5$ were detected earlier than cardiac $\alpha-M H C, M L C-2 v$ and $\beta-A R$. Icariin-induced $M L C-2 v$ expression upregulation was detected as early as $\mathrm{d} 5+2$, whereas increased expression in control cells was not observed until d 5+7. These results suggest that one of the mechanisms by which icariin is involved in differentiation is by facilitating the expression of the cardiac developmentaldependent genes in a developmentally controlled manner. In particular, icariin could enhance the development of ventricular cardiomyocytes at an early differentiation stage.

It is important to characterize the responses of cardiomyocytes derived from ES cells, and one of the key modulators of contraction is the $\beta$-AR system ${ }^{[18,19]}$, therefore in the present study the responses of the beating rate of cardiomyocytes to $\beta$-AR stimulation were determined. We confirmed that $\beta$-AR responses were well developed in cardiomyocytes derived from ES cells. The cardiomyocytes treated with icariin were more sensitive to isoprenaline than the case of in controls. The different sensitivities of the cardiomyocytes to isoprenaline may result from the different expression levels and the degree of maturity of $\beta-\mathrm{AR}^{[20]}$, the hypothesis that is supported by the results of our RT-PCR analysis.

$\mathrm{NO}$ is a potential differentiation signal that plays an important role in the differentiation of ES cells into cardiomyocytes $^{[21]}$. In most instances, NO signaling pathways are typically dependent on cGMP. The cGMP-dependent pathways are initiated by NO-induced activation of soluble guanylate cyclase by binding to heme iron. This activation results in a transient increase in the second messenger cGMP ${ }^{[22]}$. Another messenger, cAMP, also plays an important role in regulating cellular proliferation and differentiation. The effects of cAMP and cGMP are opposite. It is crucial to maintain the correct cAMP/cGMP ratio to provide the correct microenvironment for cell survival and function. Upregulation of cAMP is a key process for facilitating differentiation and inhibiting proliferation. Icariin induces the differentiation of HL-60 cells, possibly by elevating the cAMP/cGMP ratio ${ }^{[5]}$. In the present study, treatment of ES cells with icariin for 24$48 \mathrm{~h}$ resulted in an elevated cAMP concentration and cAMP/ cGMP ratio. This indicates that upregulation of cAMP concentration and cAMP/cGMP ratio is important for the differentiation of ES cells in early differentiation events, before a shift to the cardiomyocyte phenotype. In the present study, when ES cells were treated with icariin for $24-48 \mathrm{~h}$ before a shift to the cardiomyocyte phenotype, supernatant NO production was markedly elevated. The cGMP level was also elevated with icariin treatment for only $24 \mathrm{~h}$. On the basis of the results of the radioimmunoassays and the Griess reaction measurements, we suggest that the NO-cGMP pathway is only involved in the early differentiation of ES cells treated with icariin for $24 \mathrm{~h}$ before a shift to the cardiomyocyte phenotype. However, the fact that the involvement of NO was independent of cGMP in early differentiation warrants further investigation.

Further studies were aimed at the involvement of icariin in the NO signaling pathway during cardiomyocyte phenotype formation. NO is generated by the NOS family of proteins. Both NO and NOS isoforms have been shown to induce or facilitate the differentiation of several cell types, including nerve cells ${ }^{[23]}$, some tumor cell types ${ }^{[24]}$, and cardiac cells ${ }^{[25]}$. ES cell-derived cardiomyocytes have been found to have an identical pattern of NOS expression as that detected in mouse heart. In the early developmental stage, ES cell-derived cardiomyocytes displayed strong iNOS and eNOS expression. Conversely, in the late developmental 
stage, iNOS was not detected and eNOS expression was found only at low levels. iNOS was expressed only in the early cardiac differentiation stage and was important for cardiac development. Work with mouse ES cells has shown that NOS inhibitors arrest differentiation toward the cardiac phenotype, and this effect can be rescued by NO donors ${ }^{[21]}$. Orally administered icariin has been shown to increase the mRNA and protein expression of eNOS and iNOS and regulate the level of NO to enhance erectile function ${ }^{[8]}$. However, whether icariin improves cardiovascular function in part through regulating the level of NO has not been demonstrated. In the present study, an in vitro model was used to investigate the influence of NOS inhibitors on cardiac development within EB treated with icariin. AG is an effective and specific inhibitor of iNOS. During the course of differentiation, icariin facilitated the directional differentiation of ES cells into cardiomyocytes and supernatant NO concentration increased. AG decreased the endogenous NO level and arrested differentiation toward the cardiac phenotype. This effect of AG could be rescued by icariin. These findings suggest that icariin promotes the differentiation of ES cells into cardiomyocytes in part through upregulating the endogenous NO level, which may be related to inducing iNOS expression. They also indicate that NO plays an important role in normal cardiac development as a potential differentiation signaling molecule.

In conclusion, the promoting effects of icariin on cardiac differentiation depended on advancing and increasing the expression of the GATA4, Nkx2.5, $\alpha-M H C, M L C-2 v$ and $\beta$ $A R$ genes. Icariin could also increase cAMP concentration and the $\mathrm{cAMP} / \mathrm{cGMP}$ ratio, and promote endogenous NO generation during early differentiation and cardiac development.

\section{References}

1 Evans MJ, Kaufman MH. Establishment in culture of pluripotential cells from mouse embryos. Nature 1981; 292: 154-6.

2 Zhu DY, Lou YJ. Inducible effects of icariin, icaritin, and demethylicaritin on directional differentiation of embryonic stem cells into cardiomyocytes in vitro. Acta Pharmacol Sin 2005; 26: 477-85.

3 Zhu DY, Qu LH, Zhang XN, Lou YJ. Icariin-mediated modulation of cell cycle and p53 during cardiomyocyte differentiation in embryonic stem cells. Eur J Pharmacol 2005; 514: 99-110.

4 Hescheler J, Fleischmann BK, Lentini S, Maltsev VA, Rohwedel $\mathrm{J}$, Wobus AM, et al. Embryonic stem cells: a model to study structural and functional properties in cardiomyogenesis. Cardiovasc Res 1997; 136: 149-62.

5 Zhao Y, Cui Z, Zhang L. Effects of icariin on the differentiation of HL-60 cells. Natl Med J Chin 1997; 19: 53-5. Chinese

6 Lopez-Lluch D, Fernandez-Ayala DJM, Alcain FJ, Buron MI,
Quesada JM, Navas P. Inhibition of COX activity by NSAIDs or ascorbate increases cAMP levels and enhances differentiation in 1a, 25-dihydroxyvitamin $\mathrm{D}_{3}$-induced HL-60 cells. Arch Biochem Biophys 2005; 436: 32-9.

7 Bloch W, Fleischmann BK, Lorke DE, Andressen C, Hops B, Hescheler $\mathrm{J}$, et al. Nitric oxide synthase expression and role during cardiomyogenesis. Cardiovasc Res 1999; 43: 675-84.

8 Tian L, Xin ZC, Liu WJ, Yang YM, Liu G, Chen L, et al. Effects of icariin on the erectile function and expression of nitrogen oxide synthase isoforms in corpus cavernosum of arterigenic erectile dysfunction rat model. Zhonghua Yi Xue Za Zhi 2004; 84: 954-7. Chinese.

9 Metzger JM, Lin WI, Johnston RA, Westfall MV, Samuelson LC. Myosin heavy chain expression in contracting myocytes isolated during embryonic stem cell cardiogenesis. Circ Res 1995; 76: 710-9.

10 Scholz G, Pohl I, Genschow E, Klemm M, Spielmann H. Embryotoxicity screening using embryonic cells in vitro: correlation to in vivo teratogenicity. Cells Tissues Organs 1999; 165: 203-11.

11 Wobus AM, Kaomei G, Shan J, Wellner M, Rohwedel J, Guanju J, et al. Retinoic acid accelerates embryonic stem cell-derived cardiac differentiation and enhances development of ventricular cardiomyocytes. J Mol Cell Cardiol 1997; 29: 1525-39.

12 Kaomei G, Jurgen R, Anna MW. Embryonic stem cell differentiation models: cardiogenesis, myogenesis, neurogenesis, epithelial and vascular smooth muscle cell differentiation in vitro. Cytotechnology 1999; 30: 211-26.

13 Jing XK, Alexander L. Protective effects of all-trans-retinoic acid against cardiac arrhythmias induced by isoproterenol, lysophosphatidylcholine or ischemia and reperfusion. J Cardiovasc Pharmacol 1995; 26: 943-8.

14 Chen Y, Wang HL, Lou YJ. Signal transduction pathways induced by nitric oxide in rat hepatocytes. J Zhejiang Univ (Med Sci) 2002; 31: 424-8.

15 Boheler KR, Czyz J, Tweedie D, Yang HT, Anisimov SV, Wobus AM. Differentiation of pluripotent embryonic stem cells into cardiomyocytes. Circ Res 2002; 91: 189-201.

16 Lyons GE, Schiaffino S, Sassoon D, Barton P, Buckingham M. Developmental regulation of myosin gene expression in mouse cardiac muscle. J Cell Biol 1990; 111: 2427-36.

17 O'Bruen TX, Kee K, Chien KR. A morphogenetic field of MLC$2 \mathrm{v}$ gene expression in the primordial heart tube of normal and MLC-luciferase transgenic mice. Proc Natl Acad Sci USA 1993; 90: 5157-61.

18 Ali NN, Xu X, Brito-Martins M, Poole-Wilson PA, Harding SE, Fuller SJ. Beta-adrenoceptor subtype dependence of chronotropy in mouse embryonic stem cell-derived cardiomyocytes. Basic Res Cardiol 2004; 99: 1-10.

19 Wobus AM, Wallukat G, Hescheler J. Pluripotent mouse embryonic stem cells are able to differentiate into cardiomyocytes expressing chronotropic responses to adrenergic and cholinergic agents and $\mathrm{Ca}^{2+}$ channel blockers. Differentiation 1991; 48: 17382.

20 Maltsev VA, Ji GJ, Wobus AM, Fleischmann BK, Hescheler J. Establishment of b-adrenergic modulation of L-type $\mathrm{Ca}^{2+}$ current in the early stages of cardiomyocyte development. Circ Res 1999; 84: 136-45. 
21 Kanno S, Kim PKM, Sallam K, Lei J, Billiar TR, Shears LL. Nitric oxide facilitates cardiomyogenesis in mouse embryonic stem cells. Proc Natl Acad Sci USA 2004; 101: 12277-81.

22 Murad F. Cellular signaling with nitric oxide and cyclic GMP. Braz J Med Biol Res 1999; 32: 1317-27.

23 Peunova N, Enikolopov G. Nitric oxide triggers a switch to growth arrest during differentiation of neuronal cells. Nature 1995; 375: 68-73.

24 Magrinat G, Mason SN, Shami PJ, Weinberg JB. Nitric oxide modulation of human leukemia cell differentiation and gene expression. Blood 1992; 80: 1880-4.

\section{The 3rd Singapore International Neuroscience Conference (SINC)}

2006, May 23-24, Singapore

Info: The NNI Conference Secretariat

3rd SINC 2006

National Neuroscience Institute

11 Jalan Tan Tock Seng

Singapore 308433

Phn 65-6357-7538/7152

Fax 65-6256-4755

E-mail nni_secretariat@nni.com.sg

Http://www.nni.com.sg 